Journal of Animal and Veterinary Advances 11 (12): 2106-2109, 2012

ISSN: $1680-5593$

(C) Medwell Journals, 2012

\title{
Construction of Full-Length Goose Muscle cDNA Library
}

\author{
${ }^{1}$ Yongfeng Sun, ${ }^{1}$ Tongao Yang, ${ }^{1}$ Jingtao Hu, ${ }^{1}$ Zhe Hao, ${ }^{1}$ Yujian Sui, \\ ${ }^{1}$ Yingying $\mathrm{Fu},{ }^{2} \mathrm{Lu}$ Chen, ${ }^{1}$ Haiyang Zhu and ${ }^{1}$ Wei Wu \\ ${ }^{1}$ Laboratory of Animal Genetics and Breeding, College of Animal Science and Technology, \\ Jilin Agricultural University, 130118 Changchun, P.R. China \\ ${ }^{2}$ College of Animal Science and Veterinary Medicine, Jilin University, \\ 130062 Changchun, P.R. China
}

\begin{abstract}
The muscular tissue of breast was dissected from 8 weeks old Jilin White goose in the present study. The big fragment PCR Method was used to amplify double-strand cDNA based on the SMART techniques for construction of a full-length cDNA library. After digestion with restriction endonuclease Sfi I, a modified vector of pBluescript II SK-plasmid with the adaptors containing Sfi IA and Sfi IB sites was used to recombine with the cDNA products amplified. The recombinants were cloned by transformation into competent Escherichia coli $\mathrm{DH} 2 \alpha$. A plasmid cDNA library with goose muscle was constructed. The results showed that the titer of the cDNA library was $1.01 \times 10^{6} \mathrm{pfu} \mathrm{mL}^{-1}$ and the percentage of recombinant clones was $97 \%$. The length of most cDNA inserted was between 0.25 and $1.6 \mathrm{~kb}$ identified by gel electrophoresis after cDNA PCR amplification. The unigene ratio was $66.7 \%$ and the percentage of complete cDNA sequences was $80 \%$ by estimating from the 24 clones sequenced randomly. It is helpful to study muscle development of goose at molecular level in the future.
\end{abstract}

Key words: Goose, cDNA library, SMART technique, PCR amplification, China

\section{INTRODUCTION}

Constructing cDNA library is an important way to discover new genes and study genes' function. However due to the whole genome sequencing in goose was relatively lagging behind, there were few research reports on goose separation of functional genomics, gene mapping, gene mutation and regulation of gene. To a certain extent, it affected the research process of goose genetic breeding and efficiently utilizating genetic resources so, it had increasingly drawn domestic and international researchers' attention. Constructing cDNA library played an important role in discovering and cloning new goose genes also, in studying gene structure and function. In 1975 the 1st cDNA library was successfully constructed (Rougeon et al., 1975) many genes had been cloned by constructing and screening cDNA library and cDNA library construction has become a basic means for studying functional genomics.

There were many ways in cDNA library construction such as the classic cDNA Library Construction Method (Sambrook and Russell, 2002), subtractive cDNA library (Scherer et al., 1982; Diatchenko et al., 1996), solid-phase
cDNA Synthesis Method (Roeder, 1998) and standardized cDNA Library Construction Method (Soares et al., 1999). At present, commonly used methods of fulllength cDNA library construction were CAP-trappe (Caminci et al., 1996), CAPture (Edery et al., 1999), Oligo-Capping (Maruyama and Sugano, 1994), SMART (Chenchik et al., 1996) and so on.

In view of quality and quantity of goose were two important economic traits and it was difficult to make both quality and quantity existing in the breeding process of meat-type breeds or strains even it could easily lead to the major genes lost or the gene frequency decreased which controls some of potential good traits. Through constructing the cDNA library that rich of full-length coding sequence, researchers screened and identified the major genes or candidate genes for goose quality and meat production traits also, explored the genetic regulation and metabolic mechanism of goose muscle growth and development at the molecular level which had important theoretical and practical significance. In this study researchers first took Jilin white goose breast muscle as the materials using SMART technology, utilizing pBluescript $\alpha$ SK plasmid which was transformated with Sfi $\mid$ connector sequence as vector

Corresponding Author: Wei Wu, Laboratory of Animal Genetics and Breeding, College of Animal Science and Technology, Jilin Agricultural University, 130118 Changchun, P.R. China 
constructing plasmid cDNA library which was designed to separate the new full-length functional gene, in order to studying gene expression regulation in goose breast muscle.

\section{MATERIALS AND METHODS}

Experimental animals and sampling: Jilin White geese were feeded in Jilin Agricultural University goose industry R and D Center in Jilin province, Northeast of China. Under the aseptic condition, breast muscle samples were collected from 10 geese of 8 weeks old, immediately kept at $-196^{\circ} \mathrm{C}$.

Total RNA extraction and purification: Total RNA were extracted from goose muscle using Trizol (Takara Inc., Dalian, China), according to the manufacturer's instructions and then treated with DNA-free DNase I (Ambion Inc., Texas, USA) to remove any potential genomic DNA contamination. The integrity of RNA was determined by gel electrophoresis and the concentration of RNA was determined with SmartSpec Plus Spectrophotometer (Bio-Rad Inc. USA).

cDNA double-strand synthesis, digestion and fractionation: $\mathrm{SMART}^{\mathrm{TM}} \mathrm{cDNA}$ Library Construction kits (Clontech Takara Inc., Japan) were used for these process. After the first-strand cDNA synthesized, LD-PCR was performed in a volume of $100 \mu \mathrm{L}$, consisting of RT-PCR product $2 \mu \mathrm{L}, 10 \times$ Advantage 2 PCR Buffer1 $0 \mu \mathrm{L}, 50 \times$ dNTPMix $2 \mu \mathrm{L}$, 5'PCR Primer $2 \mu \mathrm{L}$, 3'PCR Primer $2 \mu \mathrm{L}, 50 \times$ Advantage 2 Polymerase Mix $2 \mu \mathrm{L}$, deionized water $80 \mu \mathrm{L}$, based on the following conditions: $95^{\circ} \mathrm{C}$ for $1 \mathrm{~min} ; 25$ cycles of $95^{\circ} \mathrm{C}$ for $15 \mathrm{sec}$ and $68^{\circ} \mathrm{C}$ for $6 \mathrm{~min}$. The amplification was performed on GeneAmp ${ }^{\circledR}$ PCR system 9700 (Applied Biosystems Inc., USA). Then, mixed $50 \mu \mathrm{L}$ PCR products and $2 \mu \mathrm{L}$ proteinase $\mathrm{K}\left(20 \mu \mathrm{g} \mu \mathrm{L}^{-1}\right)$ to a $0.5 \mathrm{~mL}$ antiseptic centrifuge tube for digestive treatment as followed: $45^{\circ} \mathrm{C}$ for $20 \mathrm{~min}$ and centrifuged then added $50 \mu \mathrm{L}$ deionized water and $100 \mu \mathrm{L}$ mixture (phenol:chloroform: isoamyl alcohol $=25: 24: 1$ ), $14000 \mathrm{r} \mathrm{min}^{-1}$ centrifuged for $5 \mathrm{~min}$, then collected upper liquid to another clean centrifuge tube, joined chloroform and isoamyl alcohol (24:1) mixture with the same volume, $14000 \mathrm{r} \mathrm{min}^{-1}$ centrifuged for $5 \mathrm{~min}$, then collected upper liquid to another clean centrifuge tube, joined $1 / 10$ volume sodium acetate of $3 \mathrm{~mol} \mathrm{~L}^{-1}, 2.5$ times volume of $95 \%$ ethyl alcohol, $14000 \mathrm{r} \mathrm{min}^{-1}$ centrifuged for $20 \mathrm{~min}$ (under room temperature condition), dumped the upper liquid, washed the sediment with $100 \mu \mathrm{L} 80 \%$ ethyl alcohol after drying added $79 \mu \mathrm{L}$ deionized water to dissolve the sediment. Then, digested with the restriction enzyme Sfi I and separated cDNA by the chromato bar SPIN-400 (Chroma technology Co. USA).
cDNA library evaluation: Calculating the titer and reorganization ratio of this library through counting the quantity of colonies, leukoplakia and locus coeruleus. Titer of cDNA library $\left(\mathrm{pfu} \mathrm{mL}^{-1}\right.$ ) $=$ Total colony number $\times$ Dilution multiple $\times 10^{3} /$ Volume of the connection product; Reorganization ratio $=$ Leukoplakia quantities/Total number of colony $\times 100 \%$.

Randomly selected 40 colonies in the titer determinaed plates and added to $1.5 \mathrm{~mL} \mathrm{LB}$ culture solution, $37^{\circ} \mathrm{C}$ shaking overnight. Then, identified the size of the inserting cDNA fragment using $\mathrm{T} 7$ and $\mathrm{T} 9$ primers, based on the following PCR conditions: $94^{\circ} \mathrm{C}$ for $4 \mathrm{~min}$, 30 cycles of $94^{\circ} \mathrm{C}$ for $45 \mathrm{sec}, 68^{\circ} \mathrm{C}$ for $45 \mathrm{sec}, 72^{\circ} \mathrm{C}$ for $1 \mathrm{~min}$ and $72^{\circ} \mathrm{C}$ for $5 \mathrm{~min}$. Selected positive clones were sequenced by Shanghai DNA Biotechnologies Co., Ltd. and sequence alignment was completed using the software of BLASTN from the World Wide Web http://www.ncbi.nlm.nih.gov/blast.

\section{RESULTS AND DISCUSSION}

Total RNA extraction and cDNA double-strand synthesis: Theoretically, cDNA library should include all genes reverse transcripted by all cellular mRNA but because of mRNA were easy degradated and with different abundance so, it was very important for checking whether the mRNA were degradated before the synthesis of the 1st-chain cDNA (Sambrook et al., 1989). In this study, detecting total RNA which had been purified by agarose gel electrophoresis, the result shown in Fig. 1. Every RNA sample had 3 clear belts $(28 \mathrm{~S}, 18 \mathrm{~S}, 5.8 \mathrm{~S})$ and $28 \mathrm{~S}, 18 \mathrm{~S} \mathrm{RNA}$ were significantly brighter than $5.8 \mathrm{~S}$ RNA, suggesting that the total RNA extracted was integrate with no degradation. Also, OD260:OD280 were between 1.6 and 1.8 suggesting that the total RNA was purity without protein or other impurity which met the requirements of cDNA library construction (Endege et al., 1999).

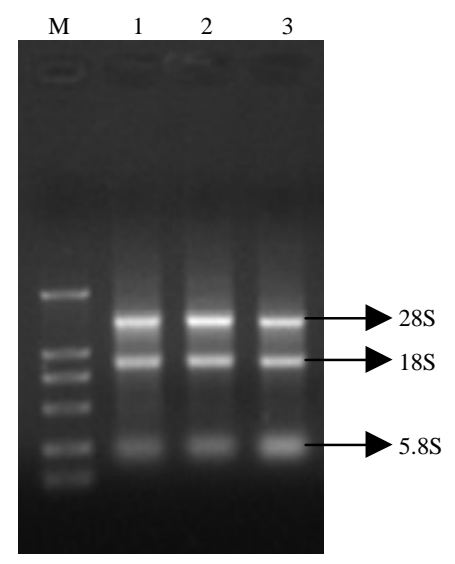

Fig. 1: Electrophoresis analysis of total RNA 
Detecting LD-PCR products by agarose gel electrophoresis, the result shown in Fig. 2a. The fragment size was $0.1 \sim 3.5 \mathrm{~kb}$ and there was a brighter belt around $0.75 \mathrm{~kb}$ so, it satisfied for cDNA library construction. Digested the cDNA products with endonuclease Sfi I and then fractionated by column chromatography to collect the first $1 \sim 8$ tube which were better for cDNA library construction.

cDNA library evaluation: The amount of the vector conjugation products obtained was $1000 \mu \mathrm{L}$ (100 reactions). Took $1 \mu \mathrm{L}$ product, transformed by the plasmid, the total number of bacterial colony obtained was 1010 plates, 978 of them were leukoplakia and locus coeruleus were 32 , the recombination rate was $97 \%$, cDNA library titer was $1.01 \times 10^{6} \mathrm{pfu} \mathrm{mL}^{-1}$.

Selected 40 positive clones randomly and identified by PCR, the results showed that most of the size of the inserts were between $0.25 \sim 1.6 \mathrm{~kb}$ (Fig. 2b). Selected 24 positive clones randomly from these recombinants for sequencing. Then removed the low quality sequences, shielded the carrier, removed the sequence under $100 \mathrm{bp}$, there were 22 valid sequences left. Unigene merged the 22 sequences, researchers got 16 unigenes and the unigene ratio was $66.7 \%$ while analyzed the full-length sequence, researchers found that 15 sequence of the whole 22 sequences had the related homogenous information including 12 full-length cDNA sequences and the completeness rate was $80.0 \%$.

According to the different vectors, cDNA library was divided into plasmid cDNA library and phage cDNA

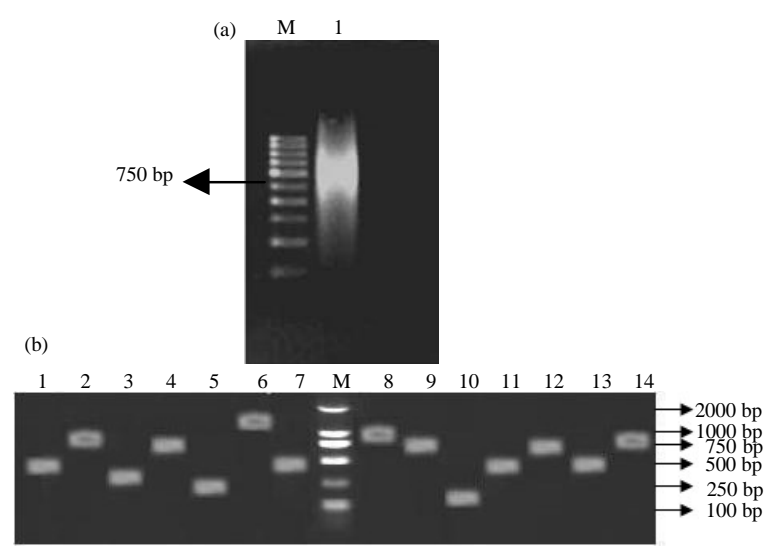

Fig. 2: Size distribution of amplified cDNA; a) Approximately $2 \mu \mathrm{L}$ of cDNA digested with SfiI I was loaded on $1.5 \%$ agarose; b) Insert cDNA fragments amplified by $\mathrm{T} 3$ and $\mathrm{T} 7$ primers from randomly selected positive clones. $\mathrm{M}, 100 \mathrm{bp}$ marker; Lane 1-14, fragments amplified by PCR from positive clones library (Ausubel et al., 2005), the former contained cDNA clones less than the latter and was considered as less connection efficiency and only for expressing higher abundance mRNA. To ensure enough number and the integrity of cloned cDNA fragments of library construction, general requirements for library capacity should not be $<1.7 \times 10^{5}$ and the average of inserting fragments size should not be $<1 \mathrm{~kb}$ (Sambrook and Russell, 2002) so as to make sure that every sequence in the genome cDNA was at least one copy existing in the restructuring library and would not damage the integrity of the cDNA fragments.

Here we used SMART technology, utilizing pBluescript $\alpha$ SK plasmid which was transformated with SfiI I connector sequence as vector, the titer of full-length cDNA library constructed was $1.01 \times 10^{6} \mathrm{pfu} \mathrm{mL}^{-}$, recombinant rate was $97 \%$ and integrity ratio of the $\mathrm{cDNA}$ sequence was $80 \%$. Thus, the main parameters all exceeded the general requirements of cDNA library construction indicating that the technology methods was feasible. In addition, researchers used SMART technology, combining the LD PCR amplification with plasmid cDNA library construction methods which was not only simplified the steps of classic cDNA library construction but also time-saving, reducing consumption of the experiment.

\section{CONCLUSION}

In this study, researchers successfully constructed Jilin white goose muscle tissue cDNA library. After determining, the titer of full-length cDNA library constructed was $1.01 \times 10^{6}$ pfu $\mathrm{mL}^{-1}$, recombinant rate was $97 \%$ and integrity ratio of the cDNA sequence was $80 \%$, most of the size of the inserts were between $0.25 \sim 1.6 \mathrm{~kb}$. It is helpful to study muscle development of goose at molecular level in the future.

\section{ACKNOWLEDGEMENTS}

This research was supported by the Science and Technology Development Program of Jilin Province Ministry of Science (No.: 20090157), Science and Technology Development Program of Jilin Province Ministry of Education (No.: 20090157) and Science and Technology Development Program of Changchun City Science and Technology Bureau (No.: 11NS12).

\section{REFERENCES}

Ausubel, F.M., R. Brent, R.E. Kingston, D.D. Moore, J.G. Seidman, J.A. Smith and K. Struhl, 2005. Short Protocols in Molecular Biology. 3rd Edn., Science Press, Beijing, China, Pages: 319. 
Caminci, P., C. Kvam, A. Kitamura, T. Ohsumia and Y. Okazaki et al., 1996. High efficiency full length cDNA cloning by biotinylated CAP trapper. Genomics, 37: 327-336.

Chenchik, A., F. Moqadam and P. Siebert, 1996. RNA: Isolation, Analysis and Synthesis. Wiley-Liss, New York, NY, USA., pp: 273-321.

Diatchenko, L., Y.F. Chrislau, A.P. Campbell, A. Chenchik and F. Mooadam et al., 1996. Suppression subtractive hybridization: A method for generating differentially regulated or tissue-specific cDNA probes and libraries. Proc. Natl. Acad. Sci. USA., 93: 6025-6030.

Edery, I., L.L. Chu and N. Sonenberyg, 1999. An efficient strategy to isolate full-length cDNAs based on an mRNA capretention procedure(CAP ture). J. Mol. Cell Biol., 15: 3363-3371.

Endege, W.O., K.E. Steinmann and L.A. Boardman, 1999. Representative cDNA libraries and their utility in gene expression profiling. J. Biotechniques, 26: $542-548$.

Maruyama, K. and S. Sugano, 1994. Oligo-capping, a simple method to replace the cap structure of eukaryotic mRNAs with oligo Ribbon nucleotides. J. Gene, 138: 171-174.
Roeder, T., 1998. Solid-phase cDNA library construction, a versatile approach. Nucl. Acids Res., 26: 3451-3452.

Rougeon, F., P. Kourilsky and B. Mach, 1975. Insertion of a rabbit $\beta$-globin gene sequence into an E. coli plasmid. J. Nucl. Acids Res., 2: $2365-2378$.

Sambrook, J. and D.W. Russell, 2002. Molecular Cloning: A Laboratory Manual. Science Publishing House, Beijing, China, pp: 532-544.

Sambrook, J., E.F. Fritsch and T.A. Maniatis, 1989. Molecular Cloning: A Laboratory Manual. 2nd Edn., Cold Spring Harbor Laboratory Press, New York, USA., ISBN-13: 9780879695774 , Pages: 397.

Scherer, G., W. Schmid and C.M. Strange, 1982. Isolation of cDNA clones coding for rat tyrosine aminotransferase. Proc. Nat. Acad. Sci. USA., 79: 7205-7208.

Soares, M.B., M.F. Bonaldo and P. Jelene, 1999. Construction and characterization of a normalized cDNA library. Proc. Nat. Acad. Sci. USA., 91: 9228-9232. 